\title{
MEETING PROFESSIONAL DEVELOPMENT NEEDS: An Alternative to the Classroom Environment
}

\author{
Hamid Y. Eydgahi, Mark Mawlawi \\ Lima Technical College
}

\begin{abstract}
:
The continuing demand for ongoing education and training, with advances in technology, is being met by application of technology, such as distance or interactive learning and are being fostered by educational institutions as well as their partners in corporate and industrial sectors.

This presentation will demonstrate an interactive instructional delivery system, through the Industrial Engineering Technology program, that has particularly been designed by the Lima Technical College for employed technical professional.
\end{abstract}

The presentation will focus on delivery of the Materials Management course, credit as well as non-credit, which provides training in Material Resource Planning (MRP) to technical personnel. This hands-on course provides flexibility and convenience while incorporating a very important learning component - interactive media with an integrated assessment system.

Specifically, the following will be presented:

- Need analysis and development of the course material,

- Principles of an interactive delivery system,

- Program assessment, and

- Future plans.

It is the authors' intent to justify the benefits and limitations of several delivery systems, while soliciting participants' input as part of this discussion.

Introduction \& Background:

Distance education is a form of alternative classroom environment between the provider (professor) and the beneficiary (student). The history of communication dates back thousands of years. The Emperor of China, 3000 years ago, sent his agents to teach the governors about conducting the business of government ${ }^{1}$. Oxford and Cambridge offered extension courses for the first time in 1858 to the general public whom, petitioned admission to educational resources ${ }^{2}$. The University of Chicago's first president, William Harper, advanced the use of correspondent education $^{3}$. The University of Iowa employed television in 1933, and in the 1950s flying aircraft brought television to various institutions of higher education (Kurtz, 1959, Brown, Lewis, and Harcleroad, 1969) as cited in Barron ${ }^{4}$. In 1969, the Open University, in the United Kingdom, was the intuition of Harold Wilson for forming a coalition of universities to take teaching into students' homes via a combination of broadcast and correspondence. Current enrollment is about 200,000. With the advent of the Internet as an additional method of delivery, the Open University has extended its reach into the global community by offering 300 of its successful distance education courses via the Internet." $\$$ \&. 
Need Analysis and Development of the Course Material:

"Knowledge is an organization's most important asset and learning is the critical technology of today's economy", (p. 200), and Norris ${ }^{8}$ (p. J-14) asserts that "To be successful in the $21^{\text {st }}$ century, learning must be available any time, any place, any where, and any how. It must be fused with work, recreation, entertainment, and personal development." According to Manjourldes ${ }^{5}$ the cost-effective, on-demand education and training via the Internet is a reality.

With unemployment at rock bottom and labor efficiency at an all-time high, the urgency to strive more effectively has challenged many organizations in developing a workforce with capable global business expertise 9 . Among many factors effecting students, access to material should be the number one priority. This need, in turn, has led to the birth of a number of innovations and educational competitors including the 'corporate universities'. The real explosion of corporate universities began about ten years ago to over 1000 today ${ }^{10}$. Perhaps more interesting, is the effort of the Engineers' and Managers' Association (EMA) union in the United Kingdom which has recently launched an MBA program for its members to enhance their career prospects ${ }^{11}$. Furthermore, in the global and Just-in-Time environment where work schedules, personal and family obligations and even distances make frequent trips to school difficult, alternative delivery systems are becoming a possible and cost-effective mode for achieving higher education not only for traditional students but more importantly for mature working professionals.

While many of us continue to be thrilled about theories, the industry's needs are becoming more competency- based and skill-based. The formal education and training of the early days are rapidly being replaced by a number of alternative delivery systems such as correspondence courses, audio conferencing, point-to-point microwave, telecourses (broadcast TV/cable, video cassettes, satellite), interactive video discs, CD-ROM, compressed videoconferencing, internet on-line, self-paced learning and many others.

Dr. Turkle, a professor at MIT, based on her research on a broad range of computer users, submitted that people are growing up in a 'culture of simulation' that has its roots in video-game technology and "these environments are premised on the ability to proceed, to learn from doing, and to do from learning" according to Biemiller ${ }^{12}$. The question is then, what do students, businesses, and industries in local, regional, national, and international markets need? With a realization of this need, Lima Technical College (LTC), in early1990s, started the evaluation and implementation of non-traditional (self-paced) opportunities for its students and the community.

LTC currently offers an Associate in Applied Science in Industrial Engineering Technology (IET), and three certificates in Methods Engineering, Production Planning, and Facilities Planning, in a completely self-paced method. The program is entirely self-paced with no regular scheduled classes and combines auxiliary subject areas such as communications, mathematics, physics, and humanities into basic objective in Industrial Engineering. The IET program consists of 7 Modules, as shown in Table 1. The course of study is keyed to a list of one hundred and ninety (190) competencies, grouped under various courses. The students, who can enter the program at anytime without the constraint of a traditional curriculum calendar, continue study until these competencies are achieved. Although there are no final examinations, there are a 
series of project assignments, which require the student to apply previously mastered skills to solve realistic problems. The interactive software used for MRP is available on the college computer network or can be downloaded onto discs by the student for applications at home. For students taking the course as non-credit, a license to use the MRP software is required.

The program uses a number of instructional tools that were listed earlier with an integrated student-centered education. The program provides further flexibility by allowing the student to enter the program at anytime regardless of the semester/quarter systems. Module four of the IET program is titled 'Production Planning and Control' and MRP and MRP II are sections presented in this module. The IET program, including MRP sections, also offers maximum flexibility for the student to set his/her study schedule. Flexible delivery is the movement of Alternative learning Systems (ALS), Lima Technical College's response to information age curriculum constraints.

Principles of an Interactive Delivery System:

Students learn MRP as part of Production and Inventory Control (Module 4), which is delivered by interactive software that contained two modes (a practice mode and a testing mode) and will be required to take a formal testing after achieving MRP certificate issued by computer. Others, who take MRP as a non-credit course, proceed through as series of interactive simulated problems solving. Once the mastery is achieved, the computer issues computer-indicating competency in MRP, a certificate.

Among benefits of computerized testing hands-on practices and flexibility, depending on the particular support system and software, are the following:

- Interactive -- that "experiences activate conditions of motivation and emotion and result in thinking, learning, perceiving, conceptionalizing, and imagining." according to Luskin $^{13}$.

- Individualization -- that "is primarily responsible for the effectiveness of the interactive software. The one to one nature of this system allows the learner to progress according to personal need." 14 .

- Immediate Feedback -- that "the computer's ability to evaluate and respond surpass by far the human instructor's ability to do so. This is a key factor in efficiency and effectiveness" of an interactive instruction system ${ }^{14}$.

The interactive aspect of the MRP module, at LTC, is crucial for effective learning and the success of recipients. Although, interactive learning had traditionally occurred in a classroom setting, with advances in technology, it is realized that the classroom is no longer a prerequisite for interaction to occur. Today, technology has made it possible to provide interaction through various innovative and non-traditional media such as CD-ROM, Teleconferencing, and Interactive Software. Through these media, the student not only has access to instructional material but is also capable of learning and applying concepts.

Program Assessment:

MRP is essentially delivered through the use of interactive software (Adventures in Operations Management) that has been developed by Quant Systems ${ }^{15}$. This interactive course is used both for credit and non-credit-training for technical personnel in industry. The non-credit-training 
course at LTC utilizes interactive learning in a self-paced format. The interactive software allows the student to not only learn the concepts but also to practice problem solving with instant electronic tutor feedback. The course is designed to not only introduce MRP to new students but also to enhance the understanding of materials requirement planning to practicing individuals in industry. This is accomplished by focusing on problem-solving skills and enhancing motivation, while enabling participants to test themselves in "a fear free" environment, thus making the process of learning more enjoyable.

By offering the course on a self-paced mode, the individual simply utilizes either the computer labs on campus or at home. Upon developing adequate confidence, the individual will then have the opportunity to switch to the certification mode (testing) and attempt to demonstrate mastery of the topic. Once the competency is successfully demonstrated, a certificate is presented to the individual as a motivating tool. While participants have the opportunity to complete course requirements at their own pace, they have the opportunity to retake the content and the test as many times as necessary (part of the optimization of the "fear free" component). There are no penalties for failing during the learning process.

Future Plans:

At LTC, we are in pursuit of continuous improvements on all programs. We plan to introduce new software that incorporates animation for design and plant layouts and implementing a number of other simulations type activities. It is also our long-term goal to develop the entire degree program online.

For the growing number of professionals who need continued training, interaction and accessibility are perhaps important factors in determining how to achieve training. Although telecourses (real-time videoconferencing) may be more accessible than classrooms, they still require the participants to leave their place of work or home and go to a remote classroom. On the other hand, CD-ROM technology, Internet and Web technologies, have greatly eliminated this requirement; the student can log-on at 'any time, any place, any where, and any how'.

As Prof. Jafari has pointed out, the business world has already taken advantage of technology and if higher education does not take necessary steps to provide such access, soon we will see '.com' instead of '.edu'. There seems to be a window of opportunity for educators to provide access to students, businesses, and industries in local, regional, national, and international markets ${ }^{16}$.

The future holds enormous opportunities for educational institutions that hold the significance of working in a 'perpetual, distributed, interactive' mode ${ }^{17}$. This concept has already been brought into existence, and while LTC currently is capable of providing videoconferencing, CD-ROM and other non-traditional deliveries, we plan to utilize desktop-to-desktop delivery using present LAN capabilities. LTC's longer-term interests include a more effective implementation of online and interactive formats toward becoming the center of the 'Smart Communities' in the next century for our global community. 
Bibliographic:

1. Wedemeyer, C. (1981). Learning at the Back Door: Reflections on Non-traditional Learning in the Lifespan. Madison, WI: The University of Wisconsin Press.

2. Jepson, N. A. (1973). The beginning of English University Adult Education - Policy and Problems. London: Michael Joseph.

3. Mackemzie; Ossian; and Christenson, E. L. (Eds.) (1971). The Changing World of Correspondence Study. University Park, PA: The Pennsylvania State University Press.

4. Barron, D. D. (1996). Distance Education in North American Library and Information Science Education: Applications of Technology and Commitment. Journal of the American Society for Information Sciences. November 1996.

5. Manjourldes, C. (1997). Global Learning. Link-up. May/June 1997.

6. Garrod, R. (1995). The Open University: 25 Years on. IRS Employment Review. December 1995.

7. Gayeski, D. M. (1993). Corporate Communication Management. Stoneham, MA: Butterworth-Heinemann, p. 200.

8. Norris, D. M. (1997). Perpetual learning as a Revolutionary Creation. ED Journal. February 11 \#2, p. J-14.

9. O’Neal, A. E. M.; Morris, D. R.; and Tooley Jr., N. E. (1997). Chevron Technical University - Teaching tomorrow's engineers today. Corporate University Review (July/August 1997).

10. Moore, T. E. (1997). The Corporate University: Transforming Management Education. Accounting Horizon. Vol. 11(1), March 1997.

11. Professional Engineering (1996). Backing for Professional Course. Special Report: Training. June 19, 1996.

12. Biemiller, L. (1997). Expert Warns of 'Culture of Simulation' in Speech at EDUCOM Conference. The Chronicle of Higher Education: Academe Today. Friday, October 31, 1997, p. 1.

13. Luskin, B. J. (1996). Toward an Understanding of Media Psychology. The Journal: Technical Horizons in Education. February 1996, Vol. 23 (7), P. 83.

14. Hannafin, M. J. and Peck, K. L. (1988). The Design, Development and Evaluation of Instructional Software. New York: Macmillan Publishing Co., p. 8.

15. Quant Systems (1996). An Overview of the Adventures Concept. Adventures in Operations Management.

16. Jafari, A. (1997). Issues in Distance Education. The Journal: Technical Horizons in Education - Online, October 1997.

17. Norris, D. M. and Poulton, S. E. (1997). Creating a Knowledge Age Vision for Your Community College. The American Association of Community Colleges, Washington: DC.

Biographic: HAMID Y. EYDGAHI, is the Dean of Engineering and Industrial Technologies at Lima Technical College in Lima, Ohio. He has a undergraduate degree in Mech. Eng. and an MBA, and is currently working on his Ph.D. He held a number of engineering and project management positions for more than ten years, before joining education.

MARK O. MAWLAWI, is the coordinator of the Industrial Engineering Technology Program at Lima Technical College in Lima, Ohio. He has an undergraduate in engineering and is currently working on his MSIE. 
Table 1

Industrial Engineering Technology at Lima Technical College

\begin{tabular}{|c|c|c|c|}
\hline & Textbook & $\begin{array}{c}\text { Audio \& } \\
\text { Video }\end{array}$ & $\begin{array}{l}\text { CD ROM, } \\
\text { Computer } \\
\text { Interactive }\end{array}$ \\
\hline $\begin{array}{l}\text { Module 1 } \\
\text { Orientation }\end{array}$ & & $\mathrm{X}$ & \\
\hline $\begin{array}{l}\text { Module 2: The Industrial Environment } \\
\text { Includes Industrial Organization, Business Decisions, Basic Manufacturing } \\
\text { Processes and Technical Mathematics }\end{array}$ & $\mathrm{X}$ & $X$ & $\mathrm{X}$ \\
\hline $\begin{array}{l}\text { Module 3: Methods Study } \\
\text { Includes Operations Analysis, Blueprint Reading, Motion and Time Study, } \\
\text { Work Sampling, Methods Time Measurements and Cost Analysis }\end{array}$ & $\mathrm{X}$ & $\mathrm{X}$ & $X$ \\
\hline $\begin{array}{l}\text { Module 4: Production Planning And Control } \\
\text { Includes Cost and Budget Control, Production \& Inventory Control (MRP), } \\
\text { Physical Distribution, Just In Time Manufacturing and Quality }\end{array}$ & $\mathrm{X}$ & $\mathrm{X}$ & $X$ \\
\hline $\begin{array}{l}\text { Module 5: Facilities Planning } \\
\text { includes Plant Location and Layout, Material Handling, Utilities and } \\
\text { Maintenance, Plant Safety }\end{array}$ & $\mathrm{X}$ & $X$ & $X$ \\
\hline $\begin{array}{l}\text { Module 6: Industrial Relations } \\
\text { Includes Union Management Relations, Wage \& Salary Administration and } \\
\text { Management Techniques }\end{array}$ & $\mathrm{X}$ & $\mathrm{X}$ & \\
\hline $\begin{array}{l}\text { Module 7: Advance Topics } \\
\text { Includes Management Science Applications, Social Responsibilities of } \\
\text { Business, Advanced Processes and Materials and Systems Engineering } \\
\text { Tech. Project }\end{array}$ & $\mathrm{X}$ & & $X$ \\
\hline
\end{tabular}

